\title{
Prevalence and factors associated with alcohol consumption during pregnancy
}

Flavia Hashizume Baptista 1

Klenia Bethania Bispo Rocha 2

Júlia Lustosa Martinelli 3

Lucimar Retto da Silva de Avó 4

Rodrigo Alves Ferreira 5

Carla Maria Ramos Germano 6

Débora Gusmão Melo 7

\footnotetext{
1-7 Departamento de Medicina. Universidade Federal de São Carlos. Rod. Washington Luís (SP-310), Km 235, Campus da UFSCar. São Carlos, SP, Brasil. CEP: 13565-905. E-mail: dgmelo@ufscar.br
}

\begin{abstract}
Objectives: to investigate the prevalence of alcohol consumption during pregnancy and its sociodemographic, reproductive and newborn-related factors.

Methods: a cross-sectional and exploratory study carried out on a sample of post-partum women, recruited daily over six months. Sociodemographic and reproductive information about the women and data concerning the newborns were collected. T-ACE questionnaire was used to identify the pattern of alcohol consumption by the women. They were divided into two groups: alcohol consumers (T-ACE score $\geq 2$ ) and non-alcohol consumers. Comparisons between the two groups were made using the unpaired t test, chi-square test or Fisher's exact test according to the type of variable analyzed. The significance level was set at $5 \%$.

Results: out of 925 women, 818 (88.4\%) agreed to participate. Among them, 60 (7.3\%) were T-ACE positive, i.e. identified as alcohol consumers. Regarding the sociodemographic information, alcohol consumption was more frequent among women who did not have a steady partner $(p=0.010)$. No reproductive variable presented a significant difference between the groups. A lower weight was observed among children of T-ACE positive mothers $(3,045 g \pm 71.0$ vs $3,192 g \pm 19.2 ; p=0.040)$.

Conclusions: identifying and characterizing women who are more susceptible to alcohol consumption during pregnancy can contribute to developing more effective public health intervention strategies.
\end{abstract}

Key words Pregnancy, Alcohol drinking, Prevalence, Epidemiologic factors 


\section{Introduction}

Alcohol abuse is considered a public health problem because, among other reasons, alcohol is a common and potent teratogenic agent. 1,2 It causes hemodynamic changes in pregnant women who compromise placental blood flow and circulates freely through all the body's fluid compartments, including vasculature, interstitial and intracellular fluids. ${ }^{3}$ Thus, the alcohol concentration is the same in a pregnant woman as in the conceptus, causing the amniotic fluid to remain impregnated with unmodified alcohol (ethanol) and acetaldehyde. 4

Alcohol that crosses the placental barrier greatly impairs the conceptus, which has a slower metabolism and detoxification mechanisms than that of an adult individual.4,2 The brain is the most susceptible organ to the effects of prenatal exposure to alcohol as every trimester of pregnancy is critical for its development. Alcohol acts in different ways, depending on the type of brain cell and embryofetal development stage, which can lead to structural and functional changes: cell death, impaired new cell formation, changes in cell migration, production of neurotransmitters and synapse formation.2,5

In 1973, a specific phenotype was identified and defined in children born to female alcoholics, called "fetal alcohol syndrome" (FAS). This is an irreversible condition characterized by typical craniofacial anomalies, intra and extrauterine growth restriction, central nervous system dysfunction (including neurological abnormalities, behavioral changes, neuropsychomotor developmental delay and intellectual disability) and various associated malformations, mainly cardiac, ocular, kidney and spinal. 6

The term "fetal alcohol spectrum disorders" (FASD) was later proposed and refers to the phenotype described in a group of children exposed to intrauterine alcohol but who do not have a complete clinical condition of FAS, although they usually experience neurobehavioral alterations. 7,8 Individuals with FASD have intellectual deficits, as well as an average intelligence quotient in the borderline range, deficiencies in different components of executive function and attention, deficiencies in information processing and numerical processing, deficiencies in spatial reasoning, visual memory, language and motor functions. 5,7

The US Centers for Disease Control and Prevention reports a prevalence of FAS between 0.2 and 1.5 per 1,000 live births, solidifying its position as one of the leading preventable causes of intellectual disability. 9 In the general infant population, the prevalence of FAS is estimated at 0.2 to 7 per 1,000 , while FASD is much more common, with an estimated prevalence of 20 to 50 per $1,000 .{ }^{8}$ A study conducted in the city of São Paulo estimated a prevalence of FAS and FASD at 1.52 per 1,000 and 38.69 per 1,000 newborns, respectively. 10

There is no consensus on the safe amount of alcohol that could be ingested during pregnancy. However, low levels of prenatal exposure may negatively affect embryofetal development.11 Considering this, the recommendation of national health services in various countries is for women to abstain completely from using alcohol throughout their pregnancy. ${ }^{11}$ In Brazil, the Ministry of Health proposes health professionals to advise pregnant women about the risks associated to alcohol use and recommends particular abstention in the first three months of pregnancy. 12

Research carried out in North America and Europe shows that the frequency of alcohol use during pregnancy varies between $8.5 \%$ and $47.3 \%$, and these rates are very dependent on the instrument used to identify alcohol consumption and the period of pregnancy that was investigated.11,13 In Brazil, studies carried out using different methodologies estimate the frequency of alcohol consumption around to be approximately 10 to $40 \%$ of pregnant women. $14-19$

T-ACE (Tolerance, Annoyed, Cut Down, and Eye-opener) was the first validated alcohol consumption screening questionnaire for use in obstetrical and gynecological practices, 20 and is routinely used in various services proving to be efficient in detecting pregnant women who consume alcohol.1,21,22 A Brazilian Portuguese version of T$\mathrm{ACE}$, translated and adapted from the original questionnaire of Sokol et al.,20 was validated by Fabbri et al. 22 in 2001 . When compared to ICD-10 criteria for alcohol abuse identification and alcohol dependence syndrome, the Brazilian version of the T-ACE questionnaire showed sensitivity and specificity coefficients of $100 \%$ and $85.6 \%$ respectively, indicating good performance as a screening tool for problems related to alcohol consumption during pregnancy. 22

This study aimed to investigate the prevalence of alcohol consumption during pregnancy among postpartum women, using the Brazilian version of the TACE questionnaire, and sociodemographic, reproductive and newborn factors associated with alcohol consumption during pregnancy.

\section{Methods}

The study was carried out in São Carlos, a city 
located in São Paulo State's geographical centre in Southeast Brazil. São Carlos has about 240,000 inhabitants (IBGE, http://www.cidades.ibge.gov.br) and approximately 3,000 births per year (Brasil, DATASUS, http://www.datasus.gov.br). In 2010, its human development index was 0.805 and was considered the $28^{\text {th }}$ most developed city in the country (Fundação SEADE, http://www.seade. gov.br). In São Carlos, prenatal coverage is higher than the average in the State of São Paulo: in 2014, for example, $86.39 \%$ of pregnant women had seven or more prenatal consultations, while in the State $76.69 \%$ of pregnant women reached this number (Fundação SEADE, http://www.seade.gov.br). São Carlos has only one maternity hospital called "Dona Francisca Cintra Silva da Irmandade da Santa Casa de Misericórdia", which is the setting of this study.

This is a cross-sectional and exploratory study carried out on a representative sample of postpartum women in São Carlos recruited daily from June 14 to December 14, 2015. The minimum sample size was established as 788 participants, considering: $95 \%$ confidence interval, $50 \%$ ratio, $3 \%$ margin of error, with correction for finite population (3,000 births per year). All post-partum women of single gestation attended by the Unified Health System (SUS), and whose children were born alive, were considered eligible and were invited to participate in the study within 48 hours after delivery. An unfavorable clinical condition in the perinatal period, which resulted in the hospitalization of women in ICU, was considered an exclusion criterion. This research was previously approved by the Human Research Ethics Committee of UFSCar (process 1,071,649) and all the participants signed an Informed Consent Form.

Data collection was performed using a predefined questionnaire with sociodemographic information of women (age, skin color, religion, marital status, schooling, work and household income), reproductive information of women (number of pregnancies, live births and abortions, the number of prenatal consultations, the type of delivery in the last pregnancy, pre-pregnancy pathologies and pathologies that occurred in the last pregnancy), as well as clinical and anthropometric data of newborns (sex, gestational age, weight and presence of a congenital defect). Furthermore, the Brazilian version of the TACE questionnaire was carried out. ${ }^{22}$

Regarding sociodemographic information, the age of women was expressed in years. The color of the skin was categorized according to the IBGE (Brazilian Institute of Geography and Statistics) considering the following options: white, black, yellow, brown or indigenous. Concerning religion, the following categories were considered: Catholic, Evangelical, Spiritist, African matrix religion (Candomblé, Umbanda, etc.) and others; the participants who affirmed that they did not profess any religion were considered agnostic and grouped with those who claimed they were atheists. Marital status was classified by "with" or "without" steady partner, and the women's group "with steady partner" included both married couples and those living together. Schooling was defined as elementary school, high school or college. In relation to work, women were classified in two categories: working or not outside the home. Household income (division of the total family's income by the number of people in the household) was categorized as: up to $1 / 2$ minimum wage per person, between $1 / 2$ and 1 minimum wage per person or more than 1 minimum wage ( $R \$ 788.00$ at the time of the study) per person.

Regarding reproductive information about the women, the number of pregnancies was categorized into: one pregnancy (primigravida), two to four pregnancies (multiparous) or five or more pregnancies (large multiparous). The number of living children was ordered into: a single living child (the newborn considered in this study), two to four children and five or more children. The number of abortions was classified as zero, one or two abortions and more than three miscarriages (habitual abortion). The number of prenatal visits was categorized into fewer than six visits and six or more visits as this is the minimum number of antenatal visits recommended by the World Health Organization. 12 The type of delivery was classified as normal or cesarean section. "Pre-pregnancy pathologies" and "pathologies that occurred in the last gestation" were categorized into: none, STD (syphilis, AIDS and HPV) or several (heterogeneous group, which included pathologies such as non-specific allergy, anemia, nephrotic syndrome, hypertension, diabetes mellitus, hypothyroidism, asthma, lupus, allergic rhinitis, polycystic ovary syndrome, sinusitis, dengue, toxoplasmosis, pneumonia and cancer).

Concerning the data about newborns, gender was categorized as female or male. The gestational age was expressed in weeks and weight in grams.

The T-ACE questionnaire consists of four main questions and each one of these questions is assigned a score and the maximum value of the questionnaire is equal to 5 (the first question is worth up to 2 points; from the second to the fourth questions, the assessment is up to 1 point). 22 When answering the questionnaire, whoever reaches a score of $\geq 2$ is considered a positive case, i.e., is identified as an 
alcohol consumer. ${ }^{20,22}$ The results were analyzed by distinguishing two groups of participants according to the T-ACE score: T-ACE negative (T-ACE score $<2$ ) and T-ACE positive (T-ACE score $\geq 2$ ).

Statistical analysis was performed using GraphPad Prism, version 5.00 for Windows (GraphPad Software, La Jolla California USA, http://www.graphpad.com). The results of the continuous quantitative variables were presented as mean \pm SEM (standard error of the mean), while the results of the discrete quantitative variables and the categorical variables were presented as simple and percentage frequencies. The groups were compared (negative T-ACE $v s$. positive T-ACE) and the statistical significance of the differences in the distribution of the variables was determined by the unpaired t-test, the chi-square test or Fisher's exact test, according to the type of variable analyzed. The significance level was set at $5 \%$.

\section{Results}

In six months of daily collections, 925 post-partum women were invited to participate in the survey and $818(88.4 \%)$ agreed. From the participants, 60 $(7.3 \%)$ were T-ACE positive, i.e., they were considered as alcohol consumers during pregnancy. Twenty-nine postpartum women (48.3\%) were positive with two points, making up the largest group of participants identified as a "positive case", 21 women $(35 \%)$ had a positive result with three points, $9(15 \%)$ with four points and $1(1.7 \%)$ with five points.

The group of postpartum women who had a score lower than the cut-off point of the T-ACE questionnaire and considered as a "negative case" comprised 758 participants (92.7\%); 94 women $(12.4 \%)$ reached a point in the questionnaire and 664 women $(87.6 \%)$ did not score (T-ACE equal to zero).

The difference in the mean age of negative TACE post-partum women $(26.5$ years \pm 0.2431$)$ and positive T-ACE (25.8 years \pm 0.8814$)$, and their distribution was not significant $(p=0.481$ and 0.101 , respectively). Data on sociodemographic information are presented in Table 1, which shows that alcohol consumption during pregnancy was more frequent among women who did not have a steady partner $(p=0.010)$.

No reproductive variables presented statistically significant differences between the groups, as can be seen in Table 2.

The results regarding the information of the newborns showed that the gender distribution was not different in the two groups: newborn male/female ratio of $1: 1$ in negative T-ACE mothers and 1:1.6 in positive T-ACE post-partum women $(p=0.080)$. The mean gestational age of the infants born to negative T-ACE women was 38.6 weeks \pm 0.1 , while in the offspring of positive T-ACE women, it was 38.4 weeks $\pm 0.3(p=0.532)$. There was an average reduction of $147 \mathrm{~g}$ in the weight of newborns whose mothers consumed alcohol during pregnancy. The mean weight among the offspring of negative T-ACE mothers was $3,192 \mathrm{~g} \pm 19.2$ and among the offspring of positive T-ACE post-partum women was $3,045 \mathrm{~g} \pm 71.0$, and this difference was significant $(p=0.040)$. During the six months of data collection, 21 newborns (2.6\%), all of them children of negative T-ACE mothers, presented birth defects and three children had multiple malformations.

\section{Discussion}

The frequency of alcohol consumption during pregnancy in the sample investigated was of $7.3 \%$, which is slightly lower than that found in other national surveys in which the frequency of alcohol consumption detected by the T-ACE ranged from $10 \%$ to $31.1 \% .10,15-19,23$

The Brazilian Ministry of Health recommends that during prenatal sessions a good bond between the mother and team of primary health care professionals is established. This helps to identify women with a propensity for alcohol abuse and guide them on the consequences of alcohol consumption during pregnancy. 12 Considering the high rate of coverage of prenatal consultations in the city of São Carlos, it is probable that the pregnant women in our study received guidance on the importance of abstinence from alcoholic beverages in the health services which they had their prenatal care, thus contributing to a lower prevalence of alcohol consumption in relation to others and studies.

In addition, 107 invited post-partum women refused to participate in our study, which represented a frequency of non-consent of $11.6 \%$. Refusals were mainly attributed to fatigue, pain related to postpartum and being occupied with mothering activities, however, they may have also contributed to a lower prevalence of alcohol consumption in the investigated sample. There is a difficulty in characterizing the intake of alcoholic beverages in pregnancy, even using more careful ways of detection by omitting or denying information. 21 Women fear the lack of confidentiality, the stigma of the diagnosis of alcoholism, and even legal repercussions such as loss of child custody.13 Many 
Table 1

Sociodemographic information of women and alcohol consumption during pregnancy in the negative T-ACE and positive T-ACE groups.

\begin{tabular}{|c|c|c|c|c|c|}
\hline \multirow[t]{2}{*}{ Variables } & \multicolumn{2}{|c|}{$\begin{array}{c}\text { negative T-ACE } \\
(n=758)\end{array}$} & \multicolumn{2}{|c|}{$\begin{array}{c}\text { positive T-ACE } \\
(n=60)\end{array}$} & \multirow[t]{2}{*}{$p$} \\
\hline & $\mathrm{n}$ & $\%$ & $\mathrm{n}$ & $\%$ & \\
\hline Age & & & & & $0.101 *$ \\
\hline$\leq 15$ & 16 & 2.1 & 1 & 1.7 & \\
\hline $16-20$ & 153 & 20.2 & 13 & 21.7 & \\
\hline $21-25$ & 203 & 26.8 & 24 & 40.0 & \\
\hline $26-30$ & 161 & 21.2 & 5 & 8.3 & \\
\hline $31-35$ & 142 & 18.7 & 9 & 15.0 & \\
\hline $36-40$ & 70 & 9.2 & 8 & 13.3 & \\
\hline$>40$ & 13 & 1.7 & - & - & \\
\hline Skin color & & & & & $0.621 *$ \\
\hline White & 324 & 42.7 & 21 & 35.0 & \\
\hline Black & 80 & 10.6 & 9 & 15.0 & \\
\hline Mix & 338 & 44.6 & 29 & 48.3 & \\
\hline Yellow & 9 & 1.2 & 1 & 1.7 & \\
\hline Indigenous & 7 & 0.9 & - & - & \\
\hline Religion & & & & & $0.423 *$ \\
\hline Catholic & 315 & 41.6 & 24 & 40.0 & \\
\hline Evangelical & 334 & 44.1 & 23 & 38.3 & \\
\hline Spiritist & 10 & 1.3 & 2 & 3.3 & \\
\hline African matrix & 4 & 0.5 & - & - & \\
\hline Atheist/agnostic & 88 & 11.6 & 11 & 18.3 & \\
\hline Others & 7 & 0.9 & - & - & \\
\hline Marital status & & & & & $0.010 * *$ \\
\hline No steady partner & 164 & 21.6 & 22 & 36.7 & \\
\hline Have a steady partner & 594 & 78.4 & 38 & 63.3 & \\
\hline Schooling & & & & & $0.631 *$ \\
\hline Elementary school & 203 & 26.8 & 14 & 23.3 & \\
\hline High school & 500 & 66.0 & 43 & 71.7 & \\
\hline Higher education & 55 & 7.3 & 3 & 5.0 & \\
\hline Work & & & & & $0.685 * *$ \\
\hline Do not work outside home & 428 & 56.5 & 36 & 60.0 & \\
\hline Work outside home & 330 & 43.5 & 24 & 40.0 & \\
\hline Household income & & & & & $0.596 * *$ \\
\hline Did not report & 249 & 32.9 & 18 & 30.0 & \\
\hline Up to $1 / 2$ minimum wage & 282 & 37.2 & 19 & 31.7 & \\
\hline From $1 / 2$ to 1 minimum wage & 130 & 17.2 & 13 & 21.7 & \\
\hline More than 1 minimum wage & 97 & 12.8 & 10 & 16.7 & \\
\hline
\end{tabular}

* Fisher's exact test; ** Chi-square test. 
Table 2

\begin{tabular}{|c|c|c|c|c|c|}
\hline \multirow[t]{2}{*}{ Variables } & \multicolumn{2}{|c|}{$\begin{array}{c}\text { negative T-ACE } \\
\quad(n=758)\end{array}$} & \multicolumn{2}{|c|}{$\begin{array}{c}\text { positive T-ACE } \\
(n=60)\end{array}$} & \multirow[t]{2}{*}{$p$} \\
\hline & $\mathrm{n}$ & $\%$ & $\mathrm{n}$ & $\%$ & \\
\hline Number of pregnancies & & & & & $0.892 *$ \\
\hline 1 & 268 & 35.4 & 23 & 38.3 & \\
\hline $2-4$ & 440 & 58.1 & 33 & 55.0 & \\
\hline 5 or more & 50 & 6.6 & 4 & 6.7 & \\
\hline Number of live children & & & & & $0.289 *$ \\
\hline 1 & 301 & 39.7 & 27 & 45.0 & \\
\hline $2-4$ & 431 & 56.9 & 33 & 55.0 & \\
\hline 5 or more & 26 & 3.4 & - & - & \\
\hline Number of abortions & & & & & $0.294 *$ \\
\hline nil & 610 & 80.5 & 45 & 75.0 & \\
\hline $1-2$ & 139 & 18.3 & 13 & 21.7 & \\
\hline 3 or more & 9 & 1.2 & 2 & 3.3 & \\
\hline Number of prenatal visits & & & & & $0.613^{*}$ \\
\hline Less than 6 & 60 & 7.9 & 3 & 5.0 & \\
\hline 6 or more & 698 & 92.1 & 57 & 95.0 & \\
\hline Type of birth in the last pregnancy & & & & & $0.402 * *$ \\
\hline Cesarean section & 488 & 64.4 & 35 & 58.3 & \\
\hline Normal & 270 & 35.6 & 25 & 41.7 & \\
\hline Pre-pregnancy pathologies & & & & & $0.778^{*}$ \\
\hline None & 650 & 85.8 & 51 & 85.0 & \\
\hline Several & 102 & 13.8 & 8 & 13.3 & \\
\hline STD & 6 & 0.8 & 1 & 1.7 & \\
\hline Pathologies that occurred in gestation & & & & & $0.612^{*}$ \\
\hline None & 444 & 58.6 & 33 & 55.0 & \\
\hline Several & 309 & 40.8 & 26 & 43.3 & \\
\hline STD & 5 & 0.7 & 1 & 1.7 & \\
\hline
\end{tabular}

* Fisher's exact test; ** Chi-square test; STD= sexually transmitted diseases.

still feel guilty and ashamed, and especially in those situations where newborns have unfavorable perinatal outcomes (malformed or premature children), it can be considered that there is bias in maternal memory and fewer women admit to drinking while pregnant.22 All these aspects can undersize the alcohol consumption statistics in pregnancy and explain even the great variability in prevalence that occurred in different studies using the same screening tool.

This research identified two variables whose results showed statistically significant differences between women who used alcohol or not during pregnancy: lower birth weight and no steady partner. These results corroborate findings from previous research. 10,15

Restriction of fetal growth is a known effect of alcohol.21 Ethanol induces the formation of oxygen free radicals, which damages cellular proteins and lipids, increasing apoptosis and impairing organogenesis. Alcohol affects the endogenous antioxidant capacity, both by lowering glutathione peroxidase levels and by generating free radicals, such as CYP2E1 which oxidizes ethanol by generating hydroxyethyl or superoxide which targets the side chains of polyunsaturated fatty acids in brain tissue. This peroxidative process can cause damage during organogenesis and results in dysfunction of the central nervous system. Furthermore, alcohol causes rapid placental vasoconstriction, due to oxidative stress, which causes a decrease in nitric oxide, and due to dysregulation of the balance of thromboxane (vasoconstrictor) and prostacyclin (vasodilator), 
reducing the supply of oxygen and nutrients to the fetus and collaborating to restrict its growth. Ethanol may also inhibit the transport of cofactors critical for fetal growth and development, such as biotin and vitamin B6. 2

The risk of infant births with low birth weight $(<2500 \mathrm{~g}$ for the term newborn) or small for gestational age increases linearly in mothers who consume a daily dose of alcohol (about $10 \mathrm{~g}$ absolute alcohol) or more. 24 A survey of 1,964 pregnant women in a public maternity hospital in the city of São Paulo found that the higher the alcohol consumption, the lower the weight, the head circumference and the length of newborns. 10

In another study carried out with 150 postpartum women from the city of Ribeirão Preto in the State of São Paulo, there was a mean reduction of $109 \mathrm{~g}$ in weight and $0.42 \mathrm{~cm}$ in the cephalic perimeter in children of mothers who consumed alcohol, identified by T-ACE. Moreover, in the female fetuses, the weight reduction was more significant (186g), suggesting a possible greater susceptibility related to the sex of the newborn.15 In our study, we also observed a greater reduction in the weight of newborn female children of positive T-ACE mothers (average decrease of $151 \mathrm{~g}$ ) compared to newborn males whose weight reduction averaged $99 \mathrm{~g}$. Future research on the fetal effects of alcohol considering the gender of the conceptus may contribute to a better understanding of this specific aspect of teratogenesis. A limitation of our study is the fact that we did not investigate the use of tobacco, a habit associated with the consumption of alcohol1,16,25,26 and known to interfere in the weight of the newborn, which may have influenced our results.

The literature also shows an association between alcohol consumption during pregnancy and not having a steady partner, as suggested in our study. Single women may also have other risk factors related to alcohol use in pregnancy such as low education, low socioeconomic status and unwanted pregnancies. 15 Unplanned pregnancies contribute to delayed recognition, leading many women to engage in risky behavior, including alcohol consumption. ${ }^{27}$

In addition to the absence of a steady partner, other maternal risk factors commonly associated with alcohol abuse are: aged over 30 years, low education, "non-white" skin color, use of tobacco and illicit drugs, as well as socio-economic vulnerability. 16,25,26,28 A recent review showed that women who are older, have lower education, are unmarried, unemployed, with lower stature, lower body mass index, nutritional status considered suboptimal, mental health problems, who suffered sexual abuse, who had fewer prenatal consultations, who are smokers, drug users and who have partners who also consumed alcohol are at increased risk of having a child with FASD. ${ }^{1}$

In São Paulo city, research carried out by Mesquita and Segre 10 identified $31.1 \%$ of the postpartum women as positive T-ACE. Among the contributing factors for alcohol abuse during pregnancy were: lack of planning pregnancy; association of alcohol use with other drugs, number of cohabitants also users of ethanol and not living with their partner.

Study of 537 women in Rio de Janeiro found that about $40 \%$ of women had used some kind of alcoholic beverages during pregnancy and beer was the most commonly cited drink (83.9\%). In this study, the prevalence of suspected cases of alcohol abuse, identified by the T-ACE (21.9\%) and the TWEAK questionnaire (26.1\%) was higher among older women (from 30 years ), low education, who classified themselves as having "non-white" skin color, who did not live with a partner and reported less social support. 16

Another study carried out in Rio de Janeiro, with 433 post-partum women, through interviews and medical record consultation at a maternity hospital, found frequency of alcohol use during gestation of $7.4 \%$. Maternal factors associated with the practice were: marital status (single mothers), maternal age older than 35 years and history of previous miscarriage. In this study, women living without partners had a nearly three-fold increased risk of consuming alcohol during the gestational period, when compared to women who lived with their partners. 29

It is important to emphasize that the risk factors presented here should not be considered in isolation as alcohol consumption during pregnancy is a complex condition involving social and biological aspects. From this perspective, women at risk of consuming alcohol in an abusive way during pregnancy can also be identified by researching certain biomarkers that check if there was exposure of the pregnant woman to alcohol. Ethanol metabolites, such as fatty acid ethyl esters (FAEEs), can be identified in blood, plasma, serum, hair, nails and meconium samples and are used to measure cumulative exposure over time. Other direct and non-oxidizing products of ethanol metabolism, such as ethyl sulfate (EtS) and ethylic glycuronide (EtG), detect whether recent alcohol consumption has occurred and can also be checked. Although it is expensive to use these biomarkers in the prenatal routine, some authors advocate their clinical utility, 
considering the relevance of the early diagnosis of risk situations for FAS and FASD. 1

Recognition of the profile of women who use alcohol improperly during pregnancy can be used to prioritize health education actions aimed at the most vulnerable population. However, it cannot be used to restrict attention to an apparently risky population as many women with suspected alcohol abuse do not meet the standard established in the literature. ${ }^{16}$ In relation to this, another limiting factor of our study was the fact that we investigated only women attended by the Brazilian Unified Health System. The inclusion of post-partum women attended by the supplementary health system could modify our results.

Pregnancy can have a positive impact on women's lives, resulting in reducing the use of harmful substances and reducing harmful effects to the conceptus. ${ }^{24}$ Moreover, considering that the risk of recurrence of FAS has been recorded at around 50 to $75 \%, 30$ identifying abusive alcohol consumption among women of childbearing age is also important to prevent conception damage in future pregnancies. More recently, experimental research in animal models has investigated the effects of antioxidants such as vitamins $\mathrm{C}$ and $\mathrm{E}$, resveratrol, astaxanthin and curcumin in alcohol-exposed fetuses. These antioxidants combat the oxidative stress caused by ethanol and, therefore, it is postulated that treating pregnant women with food supplements containing these substances could help to reverse and prevent FAS and FASD, although no protocol of supplementation has been approved for clinical use to date. Other supplements, such as folic acid, Lglutamine, boric acid and choline also appear to minimize the harmful effects of alcohol on embryofetal development and may play a therapeutic role in the future. ${ }^{2}$

Since there is no safe amount of alcohol intake during pregnancy and any amount can affect embryofetal development, 2,11 we recommend that the material published by the Ministry of Health to inform both health professionals and the general public points out the importance of abstaining from alcohol consumption throughout pregnancy explicitly, not only in the first trimester. Promoting advertising campaigns on the subject can also be an additional measure of health education.

Recognizing problems related to fetal alcohol exposure allows better adaptation of care provided to pregnant women, the newborn and her family. Taking this into account, identifying and characterizing women who are most susceptible to alcohol consumption during pregnancy can help to develop more effective intervention strategies to prevent and/or to reduce the negative impacts of alcohol use, contributing to the primary prevention of neurobehavioral changes and intellectual disabilities.

\section{Acknowledgements}

We would like to thank the São Paulo Research Foundation (FAPESP), for the financial support (grant 15/08279-0); the Coordination for the Improvement of Higher Education Personnel (CAPES) for the fellowships received through the Young Talents for Science Program. We are also grateful to Damaris de Souza Nassif and Cindy Paola for their help in building the database.

\section{References}

1. Montag AC. Fetal alcohol-spectrum disorders: identifying at-risk mothers. Int J Womens Health. 2016; (8): 311-23.

2. Gupta KK, Gupta VK, Shirasaka T. An Update on Fetal Alcohol Syndrome-Pathogenesis, Risks, and Treatment. Alcohol Clin Exp Res. 2016; 40(8): 1594-602.

3. Ramadoss J, Magness RR. Vascular effects of maternal alcohol consumption. Am J Physiol Heart Circ Physiol. 2012; 303(4): H414-21

4. Heller M, Burd L. Review of ethanol dispersion, distribution, and elimination from the fetal compartment. Birth Defects Res A Clin Mol Teratol. 2014; 100(4): 277-83.

5. Momino W, Sanseverino MT, Schüler-Faccini L. Prenatal alcohol exposure as a risk factor for dysfunctional behaviors: the role of the pediatrician. J Pediatr (Rio J). 2008; 84(Suppl 4): S76-9.
6. Jones KL, Smith DW, Ulleland CN, Streissguth P. Pattern of malformation in offspring of chronic alcoholic mothers. Lancet. 1973; 1(7815): 1267-71.

7. Memo L, Gnoato E, Caminiti S, Pichini S, Tarani L. Fetal alcohol spectrum disorders and fetal alcohol syndrome: the state of the art and new diagnostic tools. Early Hum Dev. 2013; 89 (Suppl 1): S40-3

8. May PA, Baete A, Russo J, Elliott AJ, Blankenship J, Kalberg WO, Buckley D, Brooks M, Hasken J, AbdulRahman O, Adam MP, Robinson LK, Manning M, Hoyme HE. Prevalence and characteristics of fetal alcohol spectrum disorders. Pediatrics. 2014; 134(5): 855-66.

9. Chokroborty-Hoque A, Alberry B, Singh SM. Exploring the complexity of intellectual disability in fetal alcohol spectrum disorders. Front Pediatr. 2014; 2: 90. 
10. Mesquita, MA, Segre, CAM. Frequência dos efeitos do álcool no feto e padrão de consumo de bebidas alcoólicas pelas gestantes de maternidade pública da cidade de São Paulo. Rev Bras Crescimento Desenvolvimento Hum. 2009; 19(1): 63-7.

11. DeVido J, Bogunovic O, Weiss RD. Alcohol use disorder in pregnancy. Harv Rev Psychiatry. 2015; 23(2): 112-21.

12. Brasil. Ministério da Saúde. Secretaria de Atenção à Saúde. Departamento de Atenção Básica. Atenção ao pré-natal de baixo risco/Ministério da Saúde. Secretaria de Atenção à Saúde. Departamento de Atenção Básica. $1^{a}$ ed. rev. Brasília: Editora do Ministério da Saúde, 2013. 318 p. Disponível em: http://dab.saude.gov.br/portaldab/ biblioteca.php?conteudo=publicacoes $/$ cab32

13. Chang G. Screening for alcohol and drug use during pregnancy. Obstet Gynecol Clin North Am. 2014; 41(2): 205 12 .

14. Kaup ZOL, Merighi MAB, Tsunechiro MA. Avaliação do consumo de bebida alcoólica durante a gravidez. Rev Bras Ginecol Obstet. 2001; 23(9): 575-80.

15. Freire TM, Machado JC, Melo EV, Melo DG. Efeitos do consumo de bebida alcoólica sobre o feto. Rev Bras Ginecol Obstet. 2005; 27(7): 376-81.

16. Moraes CL, Reichenheim ME. Screening for alcohol use by pregnant women of public health care in Rio de Janeiro, Brazil. Rev Saúde Pública. 2007; 41(5): 695-703.

17. Gouvea PB, Souza SNDH, Haddad MCL, Mello DF. Avaliação do consume de álcool entre gestantes cadastradas no SISPRENATAL em Londrina/ PR. Cogitare Enferm. 2010; 15(4): 624-30.

18. Souza LHRF, Santos MC, Oliveira LCM. Padrão do consumo de álcool em gestantes atendidas em um hospita público universitário e fatores de risco associados. Rev Bras Ginecol Obstet. 2012; 34(7): 296-303.

19. Costa DO, Neto PFV, Ferreira LN, Coqueiro RS, Casotti CA. Consumo de álcool e tabaco por gestantes assistidas na estratégia de saúde da família. Revista Eletrônica Gestão \& Saúde. 2014; 5(3): 934-48

20. Sokol RJ, Martier SS, Ager JW. The T-ACE questions: practical prenatal detection of risk-drinking. Am J Obstet Gynecol. 1989; 160(4): 863-68.
21. Jones KL, Bailey BA, Sokol RJ. Alcohol Use in Pregnancy: Insights in Screening and Intervention for the Clinician. Clin Obstet Gynecol. 2013; 56(1): 114-23.

22. Fabbri CE, Furtado EF, Laprega MR. Consumo de álcool na gestação: desempenho da versão brasileira do questionário T-ACE. Rev Saúde Pública. 2007; 41(5): 979-84.

23. Oliveira TR, Simões SMF. O consumo de bebida alcoólica por gestantes: estudo exploratório. Esc Anna Nery Rev Enferm. 2007; 11(4): 632-38.

24. Patra J, Bakker R, Irving H, Jaddoe VWV, Mailini S, Rehm J. Dose-response relationship between alcohol consumption before and during pregnancy and the risks of low birth weight, preterm birth and small-size-for-gestational age (SGA) - A systematic review and meta-analyses. BJOG. 2011; 118(12): 1411-21

25. McDonald SW, Hicks M, Rasmussen C, Nagulesapillai T, Cook J, Tough SC. Characteristics of women who consume alcohol before and after pregnancy recognition in a Canadian sample: a prospective cohort study. Alcohol Clin Exp Res. 2014; 38(12): 3008-16

26. Esper LH, Furtado EF. Identifying maternal risk factors associated with Fetal Alcohol Spectrum Disorders: a systematic review. Eur Child Adolesc Psychiatry. 2014; 23(10): 877-89.

27. Lepper LET, Lluka A, Mayer A, Patel N, Salas J, Xaverius PK, Kramer B. Socioeconomic status, alcohol use, and pregnancy intention in a national sample of women. Prev Sci. 2016; 17(1): 24-31

28. Lee SH, Shin SJ, Won SD, Kim EJ, Oh DY. Alcohol Use during Pregnancy and Related Risk Factors in Korea. Psychiatry Investig. 2010; 7(2): 86-92.

29. Freire K., Padilha PC., Saunders C. Factors associated to alcohol and smoking use in pregnancy. Rev Bras Ginecol Obstet. 2009; 31(7): 335-41.

30. Paintner BAA, Williams AD, Burd L. Fetal Alcohol Spectrum Disorders-Implications for Child Neurology Part 2: Diagnosis and Management. J Child Neurol. 2011; 27(3): 355-62.
Received on September 29, 2016

Final version presented on February 22, 2017

Approved on April 7, 2017 